\title{
ALKALI AND ALKALINE EARTH METAL CHLORIDE SOLUTIONS INFLUENCE SULFIDE MINERAL DISSOLUTION
}

\author{
Hariprasad Parthasarathy, David A. Dzombak, Athanasios K. Karamalidis*
} Department of Civil and Environmental Engineering, Carnegie Mellon University, Pittsburgh, PA - 15213

\author{
* Corresponding author: \\ Athanasios K. Karamalidis \\ Department of Civil and Environmental Engineering \\ Carnegie Mellon University, \\ Pittsburgh, PA - 15213 \\ Phone: 412-268-1175 \\ Email: akaramal@andrew.cmu.edu
}




\section{$47 \quad$ Abstract}

49 Alkali and alkaline metal chlorides have been considered as inert electrolyte species with

50 respect to sulfide mineral dissolution in the presence of oxidizing agents such as $\mathrm{O}_{2}$ and

$51 \mathrm{Fe}^{3+}$. Under anoxic conditions in the laboratory or the field, as exist in most saline

52 subsurface environments, the potential reactivity of alkali and alkaline metal chlorides

53 with sulfide minerals has typically been ignored. Arsenopyrite (FeAsS(s)), galena

$54(\mathrm{PbS}(\mathrm{s}))$, and pyrite $\left(\mathrm{FeS}_{2}(\mathrm{~s})\right)$ are commonly encountered sulfide mineral phases, the

55 dissolution of which affects many ecosystems. In this study, dissolution experiments with

56 these minerals were conducted under anoxic conditions with $10 \mathrm{mM}$ solutions of $\mathrm{NaCl}$,

$57 \mathrm{CaCl}_{2}$, and $\mathrm{MgCl}_{2}$ at constant $\mathrm{pH}$ of 2.56. Results show that these electrolytes affect

58 sulfide mineral dissolution under anoxic conditions, either increasing or decreasing the

59 rate. The extent to which sulfide mineral dissolution is affected is small but measurable

60 and depends on the anionic species in the mineral and cationic species in solution.

61 Specifically, the dissolution of arsenic from arsenopyrite increased with an increase in

62 cation activity in solution, while the dissolution of sulfur decreased with an increase in

63 chloride ion activity. These results suggest that sulfide mineral dissolution under anoxic

64 conditions is caused by an interaction of cations in solution with anions on the mineral

65 surface, and inhibited by the presence of competing anions in solution.

66

67

68 Keywords: sulfide minerals, arsenopyrite, sodium chloride, mineral dissolution

Highlights:

- $\mathrm{NaCl}, \mathrm{CaCl}_{2}, \mathrm{MgCl}_{2}$ influence sulfide mineral dissolution under anoxic conditions.

- Dissolution of arsenic from arsenopyrite increases with an increase in cation activity

- Dissolution of sulfur decreases with increasing chloride ion activity in solution

- Sulfide mineral dissolution under anoxic conditions is dependent on anionic species in the mineral, and cations and anions in solution. 


\section{1. Introduction}

84 Traditionally, alkali and alkaline earth metal chlorides such as $\mathrm{NaCl}, \mathrm{MgCl}_{2}$ and $\mathrm{CaCl}_{2}$

85 have been used to control bulk solution ionic strength while studying mineral dissolution

86 with higher-energy reactants. These chloride reagents typically are considered inert and

87 with little influence on dissolution aside from effect on the activity of reactants through

88 ionic strength. This is particularly true with the study of sulfide mineral dissolution for

89 which usually involve experiments conducted with oxidants such as $\mathrm{Fe}^{3+}$ and dissolved

90 oxygen (Barrett and Anderson, 1982; Ohmoto et al., 1994) or reactants such as acids

91 (Nunez et al., 1990; Awakura et al., 1980). In strongly reacting environments, effects of

92 background electrolytes on dissolution typically are negligible as compared to that caused

93 by the reactants, and hence not observable. Therefore the effect of these electrolytes as

94 possible reactants for dissolution has not been explored. With the emergence of interest in

95 aqueous environments that are anoxic and have high concentrations of alkali metal

96 chlorides, such as brines in deep saline formations, the potential for these salt solutions to

97 influence mineral dissolution merits examination.

99 The ability of sulfide minerals to react with waters and contribute to acid mine drainage

100 (AMD) and toxic metal mobilization ( $\mathrm{As}, \mathrm{Pb}, \mathrm{Cd}, \mathrm{Hg}$, etc.) has driven study of the factors

101 and conditions controlling their dissolution (Vaughan, 2005). The dissolution of sulfide

102 minerals has been studied under varying solution conditions including in the presence of 
103 alkaline metal chlorides in solution. Non-oxidative acidic dissolution of sphalerite

$104((\mathrm{Zn}, \mathrm{Fe}) \mathrm{S}(\mathrm{s}))$ and galena $(\mathrm{PbS}(\mathrm{s}))$ has been studied in the presence of sodium and

105 magnesium chloride solutions. The reported increases in dissolution were attributed to a

106 change in $\mathrm{H}^{+}$ion activity, and not determined to be an effect of the electrolyte itself

107 (Nunez et al., 1990; Awakura et al., 1980; Barrett and Anderson, 1982). Limited studies

108 have been conducted on the dissolution of pyrite $\left(\mathrm{FeS}_{2}(\mathrm{~s})\right)$ in the presence of sodium

109 chloride in solution (Ohmoto et al., 1994), and on oxidative dissolution of pyrite and

110 arsenopyrite (FeAsS(s)) in electrolyte solutions (Walker at al., 2006, Lin and Zheng,

111 1996). These studies assume the only reactants in dissolution to be $\mathrm{H}^{+}$or the oxidant

112 species, namely $\mathrm{O}_{2}$ and $\mathrm{Fe}^{3+}$, but the potential interaction of the mineral surfaces with

113 cations in solution, which could affect dissolution, has not been investigated.

115 Galena, pyrite, and arsenopyrite represent three different types of sulfide minerals based 116 on their anionic sulfide groups. Multiple experiments aimed at understanding the surface

117 speciation for these minerals have revealed the major anionic groups to be sulfide $\left(\mathrm{S}^{2-}\right)$

118 for galena (Hernan et al., 1995), disulfide $\left(\mathrm{S}_{2}{ }^{2-}\right)$ for pyrite (Nesbitt et al., 1998), and $\mathrm{As}^{-}$

119 and $\mathrm{S}^{-}$as a polyanion ([AsS $]^{2-}$ ) for arsenopyrite (Corkhill and Vaughan, 2009). Studies

120 conducted to determine the isoelectric points $\left(\mathrm{pH}_{\mathrm{i} . \mathrm{e} . \mathrm{p}}\right)$ of galena, pyrite, and arsenopyrite

121 under anoxic conditions have revealed a $\mathrm{pH}_{\mathrm{i} . \mathrm{e} . \mathrm{p}}<2$ for all three minerals (Bebie et al.,

122 1998). As a result, at a $\mathrm{pH}$ greater than 2 , the mineral surface is negatively charged and

123 could interact electrostatically with positively charged alkali and alkaline earth metal

124 cations supplied by chloride salts in solution. 
126 The objective of this study was to determine the effect of $\mathrm{NaCl}, \mathrm{CaCl}_{2}$, and $\mathrm{MgCl}_{2}$

127 solutions on the dissolution of $\mathrm{FeS}_{2}(\mathrm{~s}), \mathrm{FeAsS}(\mathrm{s})$, and $\mathrm{PbS}(\mathrm{s})$ under anoxic conditions. Of

128 particular interest was the influence of positively charged species $\left(\mathrm{H}^{+}, \mathrm{Na}^{+}, \mathrm{Ca}^{2+}\right.$, and

$129 \mathrm{Mg}^{2+}$ ), on the release of the negatively charged sulfur and arsenic species (in

130 arsenopyrite) from these minerals. For this purpose, dissolution experiments were

131 conducted in a column plug-flow reactor and anoxic influent solutions at a low $\mathrm{pH}$ to

132 avoid precipitation and mass transfer complications. Effluent concentrations of

133 constituent elements for each mineral were measured and compared to variables in the

134 experiments to determine the parameters that influenced the dissolution of these minerals

135 under anoxic conditions.

137 2. Materials and Methods

1382.1 Mineral preparation and characterization

139 Arsenopyrite, galena, and pyrite were obtained from Wards Sci. Inc. (Rochester, NY) and

140 were crushed in a porcelain mortar and pestle and size fractionated using nylon sieves to

141 a range of $150-250 \mu \mathrm{m}$. The mortar and pestle as well as sieves were soaked overnight in

$14210 \%(\mathrm{w} / \mathrm{V}) \mathrm{HNO}_{3}$ prior to use. The crushed minerals were then sonicated in $50 \%$ ethanol

143 and washed with $\mathrm{HCl}(12 \mathrm{~N}$ for arsenopyrite and pyrite, and $1 \mathrm{~N}$ for galena) based on the

144 method described by Parthasarathy et al., (2014). This enabled the removal of fine

145 particles adhering to the mineral surface and removal of oxide layers that may affect

146 dissolution measurement. The size-segregated, clean particles were analyzed by X-ray 
147 diffraction (XRD). XRD analyses confirmed the primary mineral phases were

148 arsenopyrite, pyrite, and galena for the corresponding samples. No secondary mineral

149 phases were detected in any of the mineral samples. Average mineral stoichiometry was

150 measured using a scanning electron microscope (SEM)- energy dispersive X-ray

151 spectroscopy (EDS) system. The measured stoichiometries are presented in Table 1.

152 While XRD analyses confirmed the presence of a single mineral phase and SEM analyses

153 revealed near theoretical stoichiometry, the absence of amorphous phases could not be

154 confirmed. As noted later, the solution phase Fe concentrations measured in some of the

155 dissolution experiments suggest the possible presence of some amorphous Fe phase(s).

157 Table 1. Stoichiometry of mineral samples for dissolution experiments measured by SEM-EDS

\begin{tabular}{|c|c|}
\hline Mineral & SEM-EDS Stoichiometry \\
\hline $\begin{array}{c}\text { Arsenopyrite } \\
(\mathrm{FeAsS})\end{array}$ & $\mathrm{Fe}_{1.03 \pm 0.05} \mathrm{As}_{1.01 \pm 0.05} \mathrm{~S}_{0.87 \pm 0.05}$ \\
\hline Galena $(\mathrm{PbS})$ & $\mathrm{Pb}_{0.97 \pm 0.01} \mathrm{~S}_{1.14 \pm 0.08}$ \\
\hline Pyrite $\left(\mathrm{FeS}_{2}\right)$ & $\mathrm{Fe}_{1.03 \pm 0.03} \mathrm{~S}_{1.94 \pm 0.06}$ \\
\hline
\end{tabular}

$160 \quad 2.2$ Reagents and dissolution experiments

161 Ultra high pure $\mathrm{NaCl}$ (99.9999\%, metal basis), $\mathrm{CaCl}_{2}$ (99.99\%, metal basis), and $\mathrm{MgCl}_{2}$

162 (99.99\%, metal basis) purchased from Alfa Aesar, USA, were used to make influent

163 solutions for dissolution experiments. 1 molar ultra pure $\mathrm{HCl}$ (Fisher Scientific Inc., 
164 USA) was used to adjust the $\mathrm{pH}$. All solutions were made with deionized water (18.2 $165 \mathrm{M} \Omega$; Barnstead, USA).

167 Dissolution of galena, arsenopyrite, and pyrite was studied with $10 \mathrm{mM}$ concentrations of $168 \mathrm{NaCl}, \mathrm{MgCl}_{2}$, and $\mathrm{CaCl}_{2}$ in de-oxygenated, carbonate-free solutions under nitrogen 169 atmosphere (Table 2). The $\mathrm{pH}$ was adjusted to $2.56 \pm 0.01$ by the addition of $6 \pm 0.4 \mathrm{~mL}$ of $1701 \mathrm{~N} \mathrm{HCl}$ to $2 \mathrm{~L}$ of solution to maintain a constant $\mathrm{H}^{+}$activity. The $\mathrm{pH}$ was measured using 171 an Accumet XL 60 (Fisher scientific) pH meter. To provide for direct comparison

172 between electrolytes, an additional experiment with $\mathrm{NaCl}$, with $\mathrm{Na}^{+}$activity similar to 173 that of $\mathrm{Mg}^{2+}$ and $\mathrm{Ca}^{2+}$ in $10 \mathrm{mM} \mathrm{MgCl} 2$ and $\mathrm{CaCl}_{2}$ respectively, was conducted for 174 arsenopyrite. The activities in solution were calculated using the Extended Debye-Hückel 175 equation (Benjamin, 2010), and the corresponding concentration of $\mathrm{NaCl}$ was calculated

176 to be $5.6 \mathrm{mM}$ (Table 2). Control experiments with nitrogen-purged deionized water ( $\mathrm{pH}$ 177 2.56, $\mathrm{HCl})$ were also conducted. 
184 Table 2. List of dissolution experiments conducted (every row represents an experiment conducted with each sulfide mineral). $\mathrm{T}=25^{\circ} \mathrm{C}, \mathrm{P}=1$ bar, $\mathrm{pH} 2.56$

\begin{tabular}{|c|c|c|c|c|c|}
\hline Electrolyte & $\begin{array}{c}\text { Concentration } \\
\text { (M) }\end{array}$ & $\begin{array}{c}{[\mathrm{HCl}]} \\
(\mathrm{M})\end{array}$ & $\begin{array}{c}\text { Ionic } \\
\text { Strength } \\
\text { (M) }\end{array}$ & $\begin{array}{l}\text { Anion } \\
\text { Activity }\end{array}$ & $\begin{array}{r}187 \\
\text { Cation } \\
\text { Activity } \\
189 \\
\end{array}$ \\
\hline D.I. Water & - & 0.003 & 0.0030 & 0.0028 & 0.0028 \\
\hline $\mathrm{NaCl}$ & 0.01 & 0.003 & 0.0130 & 0.0115 & $\begin{array}{c}190 \\
0.0089\end{array}$ \\
\hline $\mathrm{CaCl}_{2}$ & 0.01 & 0.003 & 0.0330 & 0.0192 & 0.00531 \\
\hline $\mathrm{MgCl}_{2}$ & 0.01 & 0.003 & 0.0330 & 0.0192 & $0.00 \$ 92$ \\
\hline $\begin{array}{c}\mathrm{NaCl} \\
\text { (Arsenopyrite } \\
\text { only) }\end{array}$ & 0.0056 & 0.003 & 0.0085 & 0.0076 & $\begin{array}{c}193 \\
0.0051 \\
194\end{array}$ \\
\hline
\end{tabular}

\subsection{Experimental setup and analytical methods}

198 Experiments were conducted in a small-scale plug-flow column system described by 199 Parthasarathy et al. (2013), under nitrogen atmosphere. Although most mineral 200 dissolution experiments are conducted in batch or mixed flow reactor systems, plug-flow 201 reactors have some advantages for study of mineral dissolution, including inherently high 202 solid-liquid ratios (Rimstidt and Newcomb, 1993). While plug flow reactor systems are 203 less desirable to determine rate laws and constants, they are useful in determining relative 
204 rates (Rimstidt and Newcomb, 1993), as in the case of this study.

206 Plug flow systems are typically not used in dissolution experiments, as the resulting data

207 can be hard to interpret (Rimstidt and Newcomb, 1993). However, for very slow 208 reactions, the analysis of data from plug flow reactor systems can be simplified, as

209 demonstrated by Parthasarathy et al. (2013). Briefly, Parthasarathy et al. (2013) showed

210 that when the rate of reaction is much slower than the rate of mass transfer, the plug-flow

211 system is under reaction rate control and the rate of a dissolution reaction can be 212 determined directly from the effluent elemental concentrations using Eq.1.

$$
k^{\prime}=\frac{\left(C_{o u t}-C_{i n}\right)}{\tau}
$$

214 where, $k^{\prime}(\mathrm{mol} / \mathrm{l} . \mathrm{s})$ is the apparent rate of arsenic dissolution, $C_{\text {out }}(\mathrm{mol} / \mathrm{L})$ is the steady 215 state effluent arsenic concentration, $C_{i n}(\mathrm{~mol} / \mathrm{L})$ is the influent arsenic concentration, and $216 \tau(\mathrm{s})$ is the residence time of the fluid in the column. The same equation (Eq. 1.) was used 217 to determine dissolution rates of galena, and pyrite.

219 The small-scale plug flow system consisted of a $5 \mathrm{~cm}$ poly ether-ether ketone (PEEK) 220 column connected to a HPLC pump capable of delivering influent solution at a constant 
221 flow rate. The column was packed with mineral and influent solution was fed at a

222 constant flow rate of $1 \mathrm{~mL} / \mathrm{min}$. The average pore volume in the column was $0.45 \pm 0.05$

$223 \mathrm{~mL}$. The masses of specific solid phase packed were $2.5 \pm 0.1 \mathrm{~g}, 2.7 \pm 0.05 \mathrm{~g}$, and $1.7 \pm 0.1 \mathrm{~g}$

224 of arsenopyrite, galena, and pyrite respectively. The reactant solutions were purged with

225 nitrogen for 20 hours prior to the experiments, to remove any dissolved oxygen and

226 carbonate in the system. Nitrogen pumping was continued through the entire duration of

227 each experiment to prevent oxygen intrusion. The entire system was placed in a $280 \mathrm{~L}$

228 glove bag (Sigma Aldrich USA), which was filled with nitrogen. The oxygen

229 concentration inside the glove bag and the dissolved oxygen in the influent solution were

230 measured using an Accumet XL 60 Dissolved Oxygen meter (Fisher scientific). The

231 detection limits were $0.1 \%$ saturation (atmospheric oxygen) and $0.01 \mathrm{mg} / \mathrm{L}$ (dissolved

232 oxygen). All dissolution experiments were conducted at ambient temperature $\left(22^{\circ} \mathrm{C}\right)$ and

233 pressure $\left(1.01 \times 10^{5} \mathrm{pa}\right)$. Effluent samples were collected at 2-hour intervals and 234 analyzed for dissolution products by inductively coupled plasma mass spectrometry (ICP-

235 MS) and ion chromatography (IC).

237 Samples collected were preserved with $5 \% \mathrm{HNO}_{3}$ (trace metal grade). Samples were 238 diluted (5x) with $5 \% \mathrm{HNO}_{3}$ and analyzed for iron and arsenic (arsenopyrite), iron

239 (pyrite), and lead (galena) using an Agilent 7700x ICP-MS equipped with a collision-

240 reaction-chamber. Polyatomic interference for $\mathrm{Fe}$ and As were reduced by conducting the

241 analysis in Helium-collision mode. A four point calibration curve for each analyte was

242 constructed before every set of samples with $r^{2}>0.99$. A multi-element standard mixture

243 from Agilent Technologies Inc. was used to prepare standard solutions and a midrange 
244 standard was used to check the calibration after every 10 samples. The detection limits

245 were $0.15 \mathrm{ppb}$ for $\mathrm{Fe}, 0.04 \mathrm{ppb}$ for $\mathrm{As}$, and $0.003 \mathrm{ppb}$ for $\mathrm{Pb}$.

247 Total sulfur was measured as sulfate by exposing the collected samples to air for 48 hours

248 prior to analysis. Sulfate was measured using an ion-suppressed chromatography system.

249 The high-pressure liquid chromatography (HPLC) system consisted of an anion

250 suppressor (AERS 500, Dionex), an anion separation column (AS-14A, Dionex) and a

251 conductivity detector (ED40 Electrochemical detector, Dionex). The eluent was $0.8 \mathrm{mM}$

$252 \mathrm{NaHCO}_{3} / 10 \mathrm{mM} \mathrm{Na}_{2} \mathrm{CO}_{3}$ at a flow rate of $1.2 \mathrm{~mL} / \mathrm{min}$ at $35^{\circ} \mathrm{C}$. The same temperature $(35$

$253{ }^{\circ} \mathrm{C}$ ) was used for the detector. The injection volume was $100 \mu \mathrm{L}$. A four-point calibration

254 was used and calibration curves were developed with $r^{2}>0.99$ for $\mathrm{SO}_{4}{ }^{2-}$. The sulfate

255 concentration was determined according to USEPA (USEPA, 1992) and Standard

256 Methods (APHA, AWWA, and WEF, 1998). The calibration curve for sulfate was

257 constructed each time a fresh eluent was used or otherwise every 20 injections. Standard

258 solutions, prepared daily with dilutions of a stock standard sulfate solution with

259 respective salts were used. The method detection limit was found to be matrix dependent

260 and varied from 1-20 ppb.

262 2.4 Data analysis

263 Effluent concentrations of $\mathrm{S}, \mathrm{As}$, and $\mathrm{Fe}$ for arsenopyrite, $\mathrm{S}$ and $\mathrm{Pb}$ for galena, and $\mathrm{S}$ and

264 Fe for pyrite were monitored with respect to time, and steady-state concentrations were

265 obtained for each experiment. Since parameters such as mass of mineral, specific surface 
266 area, flow rate, and residence time were constant for experiments with each mineral, the

267 steady state concentrations were directly compared for each mineral. The specific surface

268 areas of each mineral was measured in triplicate using the B.E.T analysis with $\mathrm{Kr}$

269 absorption isotherm before and after dissolution, and was found to not vary significantly

270 for all three minerals. The surface areas were found to be $0.330 \mathrm{~m}^{2} / \mathrm{g}, 0.125 \mathrm{~m}^{2} / \mathrm{g}$, and

$2710.009 \mathrm{~m}^{2} / \mathrm{g}$ for galena, arsenopyrite, and pyrite respectively.

272 Steady state concentrations were determined to be reached after 12 hours of dissolution, 273 if the effluent concentration was within $\pm 15 \%$ of the average over 8 hours. It must be

274 noted that effluent concentrations can be influenced by dissolution mechanisms (such as a

275 shrinking core model for galena dissolution), resulting in a broad definition of steady

276 state as detailed above. To overcome any mechanistic effects on effluent concentrations,

277 steady state values were determined by determining average concentrations over the same 278 time period for experiments with each mineral.

280 In the case of Fe release from arsenopyrite and pyrite, a large variability in effluent

281 concentration was observed, potentially due to the presence of Fe hotspots or/and 282 amorphous iron phases in natural mineral samples. However, Fe concentrations were 283 averaged over the same time frame as As and S, which resulted in large error bars for Fe 284 steady state concentrations.

286 The calculated steady state concentrations were then compared against the different 287 experimental parameters (electrolyte concentration, cation activity, ionic strength, anion 
288 activity, and electron affinity of the cation) to determine the variable with which steady-

289 state dissolution rate was most strongly correlated.

\section{3. Results}

292 The concentrations of sulfur released from each mineral and arsenic release

293 concentrations from arsenopyrite, as a function of time, are depicted in Figure 1 and

294 Figure 2 respectively. The plots follow similar trends: a high initial release of S or As

295 occurred, which gradually decreased to reach an average steady state value. Similar

296 trends have been observed with other flow-through experiments, with the high initial

297 release potentially due to preferential dissolution from cracks and surface irregularities

298 (Walker et al., 2006).

300 With $\mathrm{PbS}(\mathrm{s})$ (Figure 1A) and FeAsS(s) (Figure 1C), the highest sulfur effluent 301 concentrations were observed in the absence of chloride salts in solution (i.e. $\mathrm{HCl}$ 302 solution at $\mathrm{pH}$ 2.56). However, in the case of pyrite, the release rate of sulfur was highest

303 with $10 \mathrm{mM} \mathrm{NaCl}$ (Figure 1B). Experiments with $10 \mathrm{mM} \mathrm{MgCl}_{2}$ and $10 \mathrm{mM} \mathrm{CaCl}_{2}$, with 304 similar chloride ion activities resulted in similar effluent concentrations of S for all three 305 minerals.

307 The dissolution of FeAsS(s) was found to follow two distinct trends. While the effluent 308 sulfur concentrations decreased in the presence of chloride salts (Figure 1C) in solution, 
309 the steady state concentrations of As increased in the presence of chloride salts in 310 solution (Figure 2). In experiments with the same cation activity, $\left(\mathrm{Na}^{+}\right.$in $5.6 \mathrm{mM} \mathrm{NaCl}$, 311 and $\mathrm{Mg}^{2+}$ and $\mathrm{Ca}^{2+}$ in $10 \mathrm{mM} \mathrm{MgCl}_{2}$ and $\mathrm{CaCl}_{2}$ respectively) similar steady state As 312 concentrations were observed. 

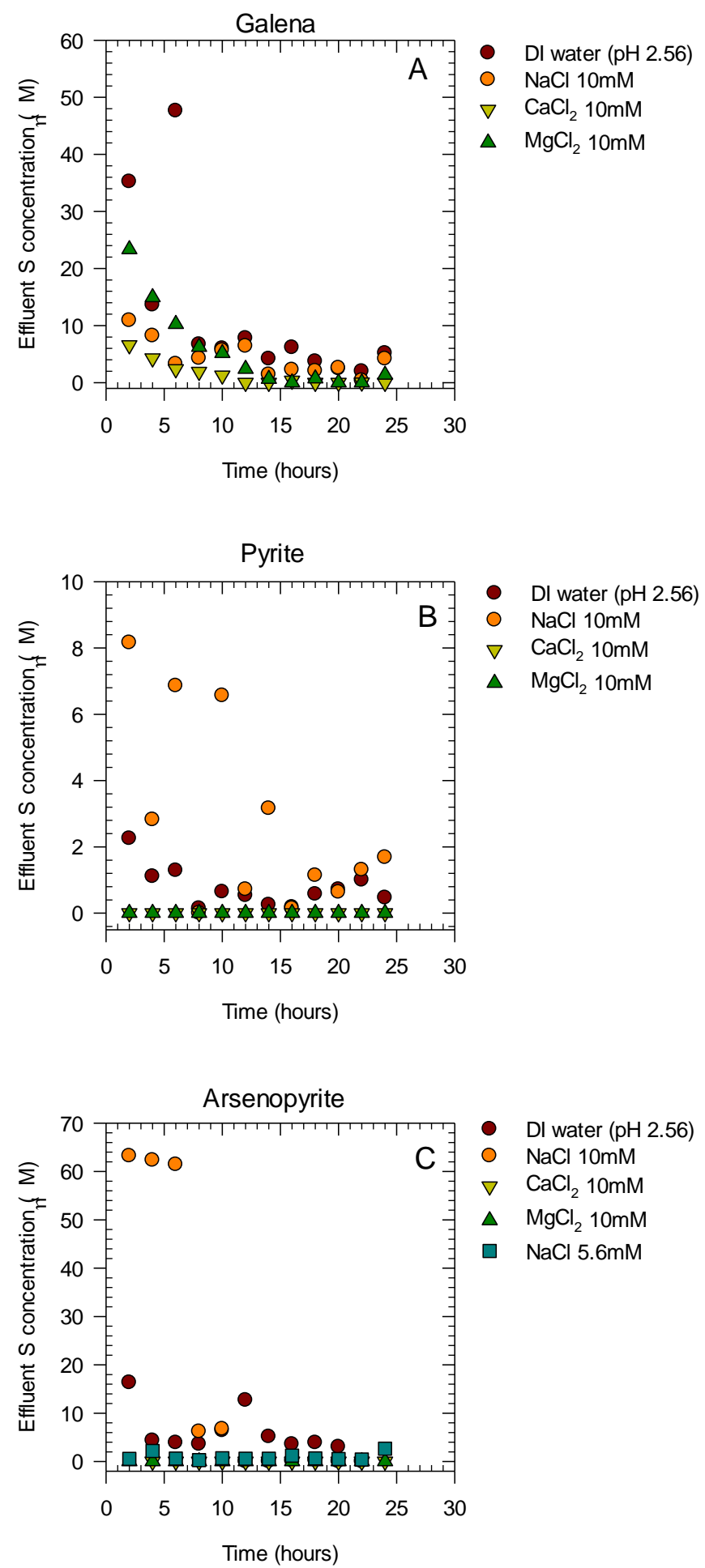

314 Figure 1. Effluent concentrations $(\mu \mathrm{M})$ of S released from (A) Galena, (B) Pyrite, and

(C) Arsenopyrite, as a function of time. $\mathrm{T}=25^{\circ} \mathrm{C}, \mathrm{P}=1 \mathrm{bar}, \mathrm{pH}=2.56$. 


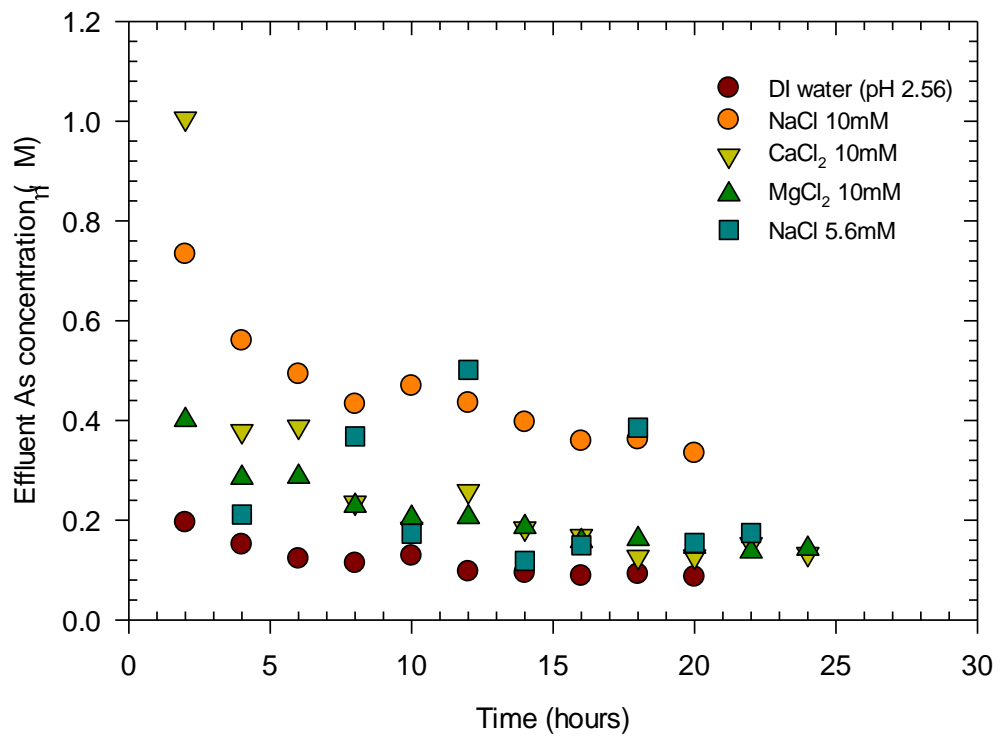

317 Figure 2. Effluent concentration $(\mu \mathrm{M})$ of As released from arsenopyrite as a function of time. $\mathrm{T}=25^{\circ} \mathrm{C}, \mathrm{P}=1$ bar, $\mathrm{pH}=2.56$.

320 The dissolution of all three sulfide minerals was found to be non-stoichiometric, i.e., the

321 molar ratios in solution of elements dissolved from the solids were not the same as the 322 ratios in the solids. The effluent concentrations of individual elements of the three 323 minerals were plotted against each other as depicted in Figure 3 (A-D). As seen in Figure $3243 \mathrm{~A}$, the dissolution of arsenopyrite resulted in a higher release of Fe as compared to As, 325 in all cases except for the experiment with $10 \mathrm{mM} \mathrm{MgCl}_{2}$ for which nearly stoichiometric 326 release quantities were observed. In general, the release ratios moved closer to the 1:1 327 (Fe:As) ratio upon addition of chloride salts in solution. In the case of sulfur and arsenic 328 release from arsenopyrite (Figure 3B), in the absence of chloride salts in solution (i.e with $329 \mathrm{HCl}$ solution at a $\mathrm{pH}$ of 2.56), sulfur was preferentially released from arsenopyrite. On 
330 the addition of chloride salts, this ratio tended towards 1 , consistent with an increase in

331 arsenic release and decrease in effluent $\mathrm{S}$ concentration. While a relatively similar trend

332 was observed with galena dissolution (Figure 3C), a large scatter in dissolution

333 stoichiometry was observed with pyrite dissolution (Figure 3D). These trends suggest

334 preferential dissolution of arsenic from arsenopyrite, and a reduction of S dissolution

335 from galena and pyrite when chloride salts were added to solution.

336 

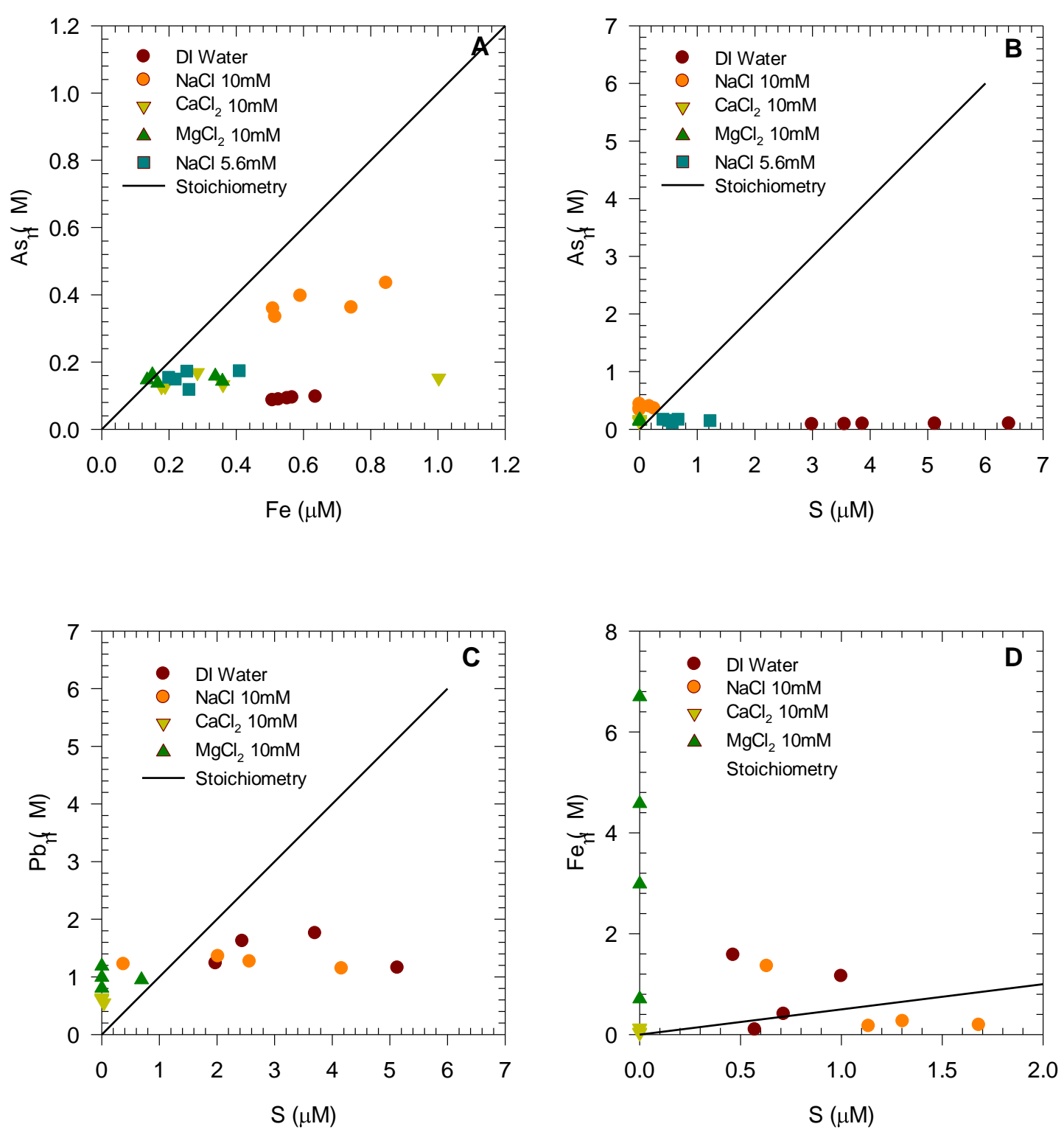

339 Figure 3. Stoichiometry of dissolution of (A and B) Arsenopyrite, (C) Galena, and (D)

340 Pyrite with chloride salts in solution. The blue line in each plot represents the solid phase 341 stoichiometric ratio for the mineral.

342 To further analyze this non-stoichiometric behavior, the mean effluent concentrations for 
343 the minerals, averaged over the last 8 hours of each experiment, were calculated and

344 compared to different experimental parameters. Correlation between the effluent

345 elemental concentrations and experimental parameters was analyzed by determining the

346 Spearman's rank correlation coefficient ( $\rho$ ), and the corresponding p-value to test if the

347 correlation coefficient was significantly different from zero. Plots for sulfur release from

348 the three minerals, and arsenic release from arsenopyrite depicting the parameter with

349 strongest correlation to dissolution rates are shown in Figure 4. Each point on the plots

350 represents a single experiment, with the error bars depicting $\pm 1 \sigma$ uncertainty in steady

351 state concentrations. Since $\mathrm{H}^{+}$activity, temperature and pressure were constant for all

352 experiments, they were not considered in the correlation analysis.

354 The results show that dissolution of the three sulfide minerals under anoxic conditions

355 was affected by the presence of alkali and alkaline earth metal chlorides in solution. In 356 general, the steady state release concentrations of sulfur for all three minerals decreased

357 in the presence of alkaline metal chlorides, while the effluent concentrations of As

358 increased in arsenopyrite dissolution, as depicted in Figure 4. A table summarizing these 359 steady state concentrations is also presented (Table 3).

362 Table 3. Steady state effluent release concentrations of Sulfur for all three minerals and 363 As for arsenopyrite. 


\begin{tabular}{|c|c|c|c|c|}
\hline \multirow{2}{*}{ Electrolyte } & \multicolumn{2}{|c|}{$\begin{array}{c}\text { Steady State Effluent Sulfur Concentration } \\
\text { (micro M) }\end{array}$} & $\begin{array}{c}\text { Steady state As } \\
\text { concentration } \\
\text { (micro M) }\end{array}$ \\
\cline { 2 - 4 } & Galena & Arsenopyrite & Pyrite & 0.091 \\
\hline $\begin{array}{c}\text { D.I Water }(\mathrm{pH} \\
2.56)\end{array}$ & 3.93 & 3.89 & 0.69 & 0.154 \\
\hline $5.6 \mathrm{mM} \mathrm{NaCl}$ & - & 0.65 & - & 0.404 \\
\hline $10 \mathrm{mM} \mathrm{NaCl}$ & 2.93 & 0.06 & 1.19 & 0.141 \\
\hline $10 \mathrm{mM} \mathrm{CaCl}{ }_{2}$ & 0.07 & BDL & BDL & 0.149 \\
\hline $10 \mathrm{mM} \mathrm{MgCl} 2$ & 0.25 & BDL & BDL & 0.19 \\
\hline
\end{tabular}

BDL: Below Detection Limit

366 The steady state sulfur concentrations for dissolution of all three minerals showed a

367 correlation to the ionic strength of the solution. In particular, the Spearman's correlation

368 analysis revealed that the steady-state $\mathrm{S}$ concentrations exhibit strong monotonic

369 correlations with calculated chloride ion activity (Figure 4A, 4B, and 4C). Spearman's $\rho$

370 was found to be -0.933 ( $p$-value $<1 \mathrm{E}-04$ ) for $\mathrm{S}$ release from arsenopyrite, -0.847 ( $\mathrm{p}$-value

$371<1 \mathrm{E}-04)$ for $\mathrm{S}$ release from galena, and -0.792 (p-value $<3 \mathrm{E}-04)$ for $\mathrm{S}$ release from

372 pyrite, which suggests a decrease in S release with increasing chloride ion activity in 373 solution.

375 The steady state arsenic release from arsenopyrite, on the other hand, did not exhibit a 376 strong correlation to chloride ion activity, but displayed a strong positive correlation to 377 the activity of cations (Figure 4D) in solution (Spearman's $\rho=0.757$, with a p-value $<$ 378 1E-04) suggesting that the dissolution of arsenic increases with an increase in the activity 
379 of cations in solution.

380

381 In addition, while the steady state concentrations of $\mathrm{Pb}$ also showed a strong negative, 382 monotonic correlation to chloride ion activity (Spearman's $\rho=-0.853$, with a p-value $<$ 383 2E-04), Fe release from arsenopyrite and pyrite did not correlate with any of the 384 experimental parameters in this study, potentially due to the dissolution of iron from 385 amorphous Fe phases in these naturally sourced mineral samples. 

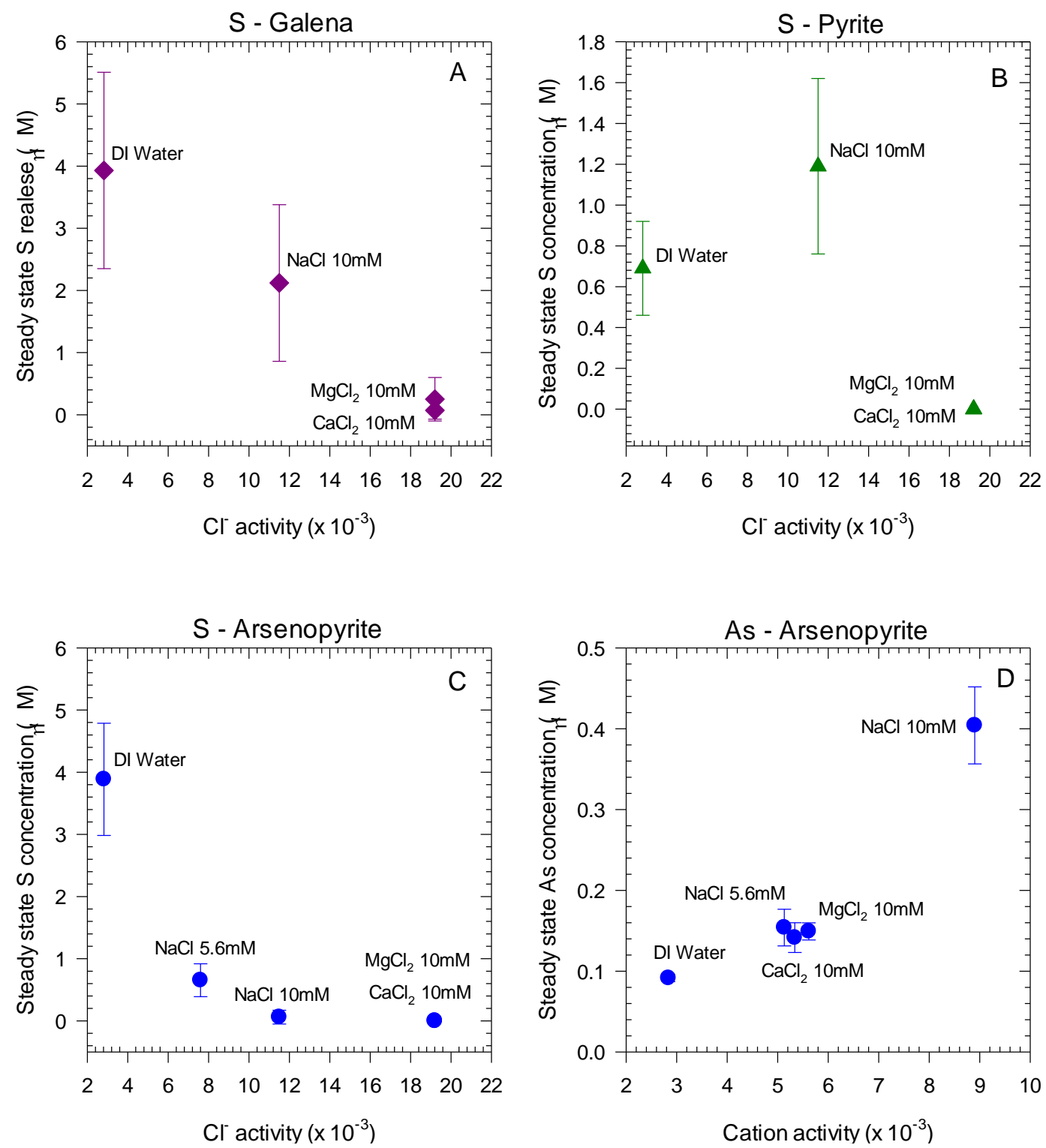

387 Figure 4. Dissolution of sulfide minerals is dependent on solution species activity. (A)

388 Steady state $\mathrm{S}$ release from $\mathrm{PbS}(\mathrm{s})$ as a function of chloride ion activity. (B) Steady state $\mathrm{S}$ release from $\mathrm{FeAsS}(\mathrm{s})$ as a function of chloride ion activity (C) Steady state $\mathrm{S}$

390 concentration from $\mathrm{FeS}_{2}$ (s)as a function of chloride ion activity, and (D) Steady state As 391 concentration from $\mathrm{FeAsS}(\mathrm{s})$ as a function of cation activity. $\mathrm{T}=25^{\circ} \mathrm{C}, \mathrm{P}=1 \mathrm{bar}, \mathrm{pH}$ 


\section{4. Discussion}

394 From the results obtained, it is clear that alkali and alkaline metal chloride salts in

395 solution can affect the dissolution of sulfide minerals. One approach to interpretation of

396 these dissolution results is to consider the reaction of sulfide minerals with solutions of

397 alkali and alkaline metal chlorides as interactions between the anions on the mineral

398 surface and the cations in solution. A schematic depicting these interactions is presented

399 in Figure 5. The anions on the mineral surface $\left(\mathrm{S}^{2-}, \mathrm{S}_{2}{ }^{2-}, \mathrm{S}^{-}\right.$, and $\left.\mathrm{As}^{-}\right)$exhibit nucleophilic

400 properties arising from the availability of lone pairs of electrons, while the cations in

401 solution $\left(\mathrm{H}^{+}, \mathrm{Na}^{+}, \mathrm{Mg}^{2+}, \mathrm{Ca}^{2+}\right)$ can act as electrophiles due to their ability to

402 accommodate an electron pair from donor atoms (Pearson, 1968). We hypothesize that

403 the dissolution process is based on interactions between nucleophilic anions on the

404 mineral surface and electrophilic cations in solution and depends on two factors: (i)

405 nucleophilic reactivity of the anions on the surface, and (ii) activity of other anions in

406 solution that may compete with the surface nucleophiles. 


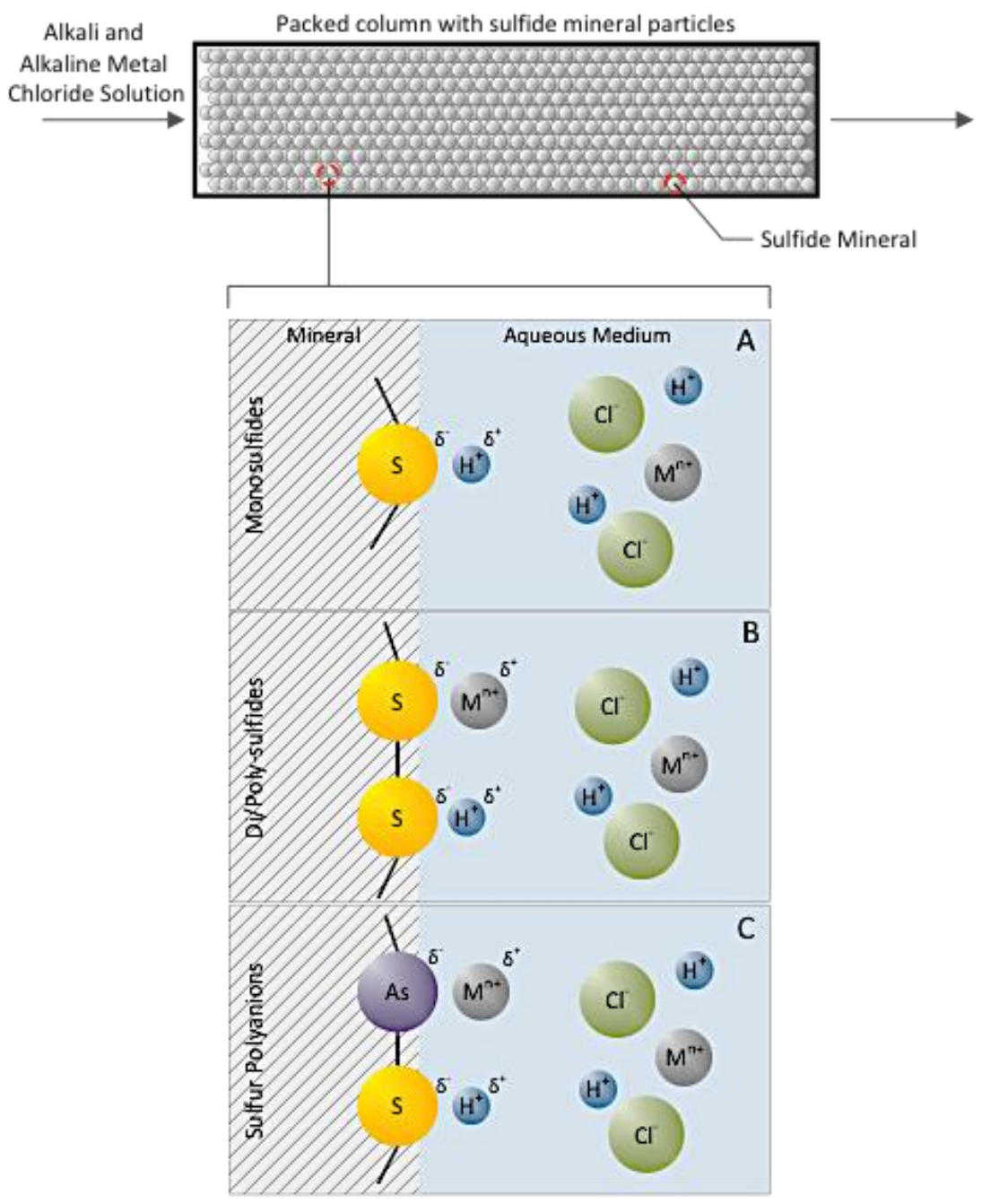

410 Figure 5. Schematic of the dissolution of sulfide minerals under anoxic conditions with

411 alkali and alkaline metal chlorides in solution. Three kinds of nucleophilic anions on

412 sulfide minerals are depicted - (A) Monosulfides; (B) Disulfides/Polysulfides; and (C)

413 Sulfur-Arsenic polyanion.

414

4154.1 Nucleophilic reactivity of anions on the surface

416 The nucleophilic reactivity of a species is measured by the rate of reaction with a specific 
417 electrophilic substrate (Larson and Weber, 1994; Edwards and Pearson, 1962). Generally,

418 nucleophilic reactivity is correlated to basicity, or the ability of a species to take up a

419 proton, and the polarizability of the species (Metzler and Metzler, 2001; Larson and

420 Weber, 1994; Edwards and Pearson, 1962). The relationship of nucleophilic reactivity to

421 basicity is implicit in the fact that nucleophile-electrophile interactions are generalized

422 acid-base type reactions (Larson and Weber, 1994; Edwards and Pearson, 1962), and

423 hence an increase in basicity is expected to lead to an increase in nucleophilic character.

424 However, the proton is unique in that it does not face any restrictions in its interactions

425 with a nucleophile. Any other electrophile will be restricted by its additional electrons

426 due to the constraints of the Pauli's exclusion principle (Edwards and Pearson, 1962).

427 The polarizability, or the ease with which the electron distribution around a chemical

428 group can be distorted (Metzler and Metzler, 2001), enables the nucleophilic species to

429 accommodate the additional electrons of electrophiles, thereby reducing the constraints of

430 the Pauli's principle.

431

432 The effect of polarizability is evident in the release of As from FeAsS(s). The 433 polarizability of bonding and nonbonding electrons away from the nucleophiles reduces

434 repulsions due to Pauli's exclusion and increases nucleophilic character (Metzler and 435 Metzler, 2001; Edwards and Pearson, 1962). Owing to the opposing trends of 436 polarizability and electronegativity in the periodic table (Carey and Sundberg, 2007), 437 arsenic is a better nucleophile than the sulfur species. This polarizability of $\mathrm{As}^{-}$enables 438 greater interaction with electrophiles (e.g. $\mathrm{Na}^{+}, \mathrm{Ca}^{2+}, \mathrm{Mg}^{2+}$ ) (Figure 5C) in solution, 439 which results in an increase of As release with an increase in cation activity (Figure 4D). 
440 However, it is possible for a species to exhibit low nucleophilic reactivity towards metal

441 cations but be strongly binding to the proton (Pearson, 1963), as observed in the S

442 species, which is more reactive to $\mathrm{H}^{+}$than to the other cationic species $\left(\mathrm{Na}^{+}, \mathrm{Ca}^{2+}, \mathrm{Mg}^{2+}\right)$

443 (schematically depicted in Figure 5A). Previous dissolution experiments under anoxic

444 conditions and in the absence of cations other than $\mathrm{H}^{+}$report that rates of dissolution of

445 galena, pyrite, and sphalerite are dependent on $\mathrm{H}^{+}$activity (Sun et al., 1991;

446 Weerasooriya and Tobschall, 2005). Proposed reaction mechanisms involve the

447 protonation of the negatively charged surface resulting in a charged surface complex that

448 subsequently dissociates leading to mineral dissolution (Sun et al., 1991; Weerasooriya

449 and Tobschall, 2005).

451 Although the minerals have a common electron donor atom in sulfur, different sulfur

452 groups can exhibit slightly different nucleophilic reactivities due to differences in charge

453 of the sulfur atom ( -1 in disulfides and -2 in sulfides) and polarizability (Metzler and

454 Metzler, 2001; Pearson, 1968). This difference in sulfur speciation can result in

455 differences in polarizability of the $\mathrm{S}$ species on these sulfide minerals. The marginal

456 increase in $\mathrm{S}$ release from pyrite upon reaction with $10 \mathrm{mM} \mathrm{NaCl}$ (Figure 4B) may be

457 attributed to the difference in polarizability of the disulfide species on pyrite as compared

458 to the sulfide species on galena. However, a more detailed set of experiments on pyrite

459 dissolution needs to be conducted to examine this effect further and test the polarizability

460 difference hypothesis. 
463 As described earlier, the dissolution of sulfur from sulfide minerals can be understood as

464 an interaction of the sulfur nucleophile with protons in solution. Since the $\mathrm{pH}$ of all

465 electrolyte solutions was fixed, the dissolution of sulfur from any particular mineral was

466 not expected to vary, irrespective of the electrolyte in solution. However, results depicted

467 in Figures 4A, 4B, and 4C show a decreasing monotonic relationship between effluent

468 sulfur concentrations and chloride ion activity in solution. This suggests that the

469 interactions between electrophilic cations in solution and the anions on the mineral

470 surface may also be dependent on other anions present in solution.

472 The presence of chloride ions in solution reduces the interaction of protons with the 473 mineral surface, resulting in a decrease in dissolution of sulfur. As depicted in Figures $4744 \mathrm{~A}, 4 \mathrm{~B}$, and $4 \mathrm{C}$, highest effluent sulfur release is observed in the absence of chloride salts 475 in solution (D.I water, $\mathrm{pH}$ 2.56), where the protons are relatively free to interact with the 476 mineral surface. With $\mathrm{NaCl}$ solutions, the interaction of protons and the mineral surface 477 is inhibited by the presence of chlorides in solution leading to lower sulfur release. The 478 release of sulfur from all three minerals is lowest in the presence of $\mathrm{CaCl}_{2}$, and $\mathrm{MgCl}_{2}$, 479 due to the excess chloride ions in solution that strongly shield the interaction of protons 480 and surface.

482 The shielding effect of $\mathrm{Cl}^{-}$is observed only with the interaction of protons with the 483 mineral surfaces. The high electronegativity of $\mathrm{Cl}^{-}$limits its nucleophilicity and its effect 
484 of inhibiting the interactions between the cations and $\mathrm{As}^{-}$is low in the range of 485 concentrations studied. Hence, similar cation activities yield similar steady state 486 dissolution concentrations, even with differences in the activity of $\mathrm{Cl}^{-}$(Figure 4D). At

487 higher $\mathrm{Cl}^{-}$activities, the inhibitory effect on dissolution may be higher.

\section{$490 \quad$ 5. Conclusions and implications}

491 From study of sulfide mineral dissolution under anoxic conditions in the presence of

492 different concentrations of the alkali and alkaline metal chloride salts $\mathrm{NaCl}, \mathrm{MgCl}_{2}$, and

$493 \mathrm{CaCl}_{2}$, it is clear that the composition and abundance of such electrolytes affect sulfide

494 mineral dissolution. The rate of dissolution of sulfide minerals under anoxic conditions is

495 controlled by the relative activities of the reactive cation $(\mathrm{s})\left(\mathrm{H}^{+}\right.$for galena and pyrite,

$496 \mathrm{H}^{+} / \mathrm{Na}^{+} / \mathrm{Ca}^{2+} / \mathrm{Mg}^{2+}$ for arsenopyrite in this study) and the inhibitory anion(s) $\left(\mathrm{Cl}^{-}\right.$in this

497 study) in solution. The propensity of a sulfide mineral surface to react with a cation is

498 dependent on the nucleophilicity of the anionic species in the mineral surface. In general,

499 the rate of dissolution of sulfur decreased in the presence of alkali and alkaline metal

500 chlorides. The case of arsenic release from arsenopyrite was an exception as FeAsS(s)

501 contains a second and stronger nucleophilic group in As-.

503 While this study offers insights into the interaction of electrolytes with sulfide mineral

504 surfaces under low electrolyte concentration conditions, high concentration conditions 
505 remain unexplored. However, certain implications of this work can be extended to

506 geologic systems. The effect of brines on mineral dissolution will be driven by their

507 compositions. With $\mathrm{Na}-\mathrm{Ca}-\mathrm{Cl}$ brines, the extent to which sulfide mineral dissolution

508 occurs will depend on the relative concentrations of $\mathrm{Cl}^{-}, \mathrm{Na}^{+}$, and $\mathrm{Ca}^{2+}$. Further, an

509 approach based on electrophile-nucleophile interactions is not necessarily limited to

510 sulfide minerals but could be valid for any solid surface that contains potential donor

511 atoms including but not limited to cyanides, thiocyanides, and carbides.

512

513 In this study, an inhibitory effect of $\mathrm{Cl}^{-}$on cation-stimulated sulfide mineral dissolution

514 was observed. This inhibitory effect will likely vary depending on the anion and its

515 tendency for interaction with protons and other cations in solution. Such interactions are

516 dependent on the basicity and nucleophilicity of the specific electrolyte anion. For

517 instance, with respect to halides, basicity decreases but nucleophilicity increases down

518 the group of the periodic table (Carey and Sundberg, 2007). Therefore, $\mathrm{F}^{-}$is expected to

519 have a higher inhibitory effect on $\mathrm{H}^{+}$while $\mathrm{I}^{-}$ion would inhibit other cations to a larger

520 extent.

521

522

523 Acknowledgments: Detailed results of the dissolution experiments are presented in the

524 supplementary section.

525 Gratitude is expressed to Mr. John Steigmeier, Carnegie Mellon University (CMU) for 
526 his help with performing XRD analysis on the samples. We also thank Dr. Matt Hotze

527 and Mr. Clint Noack for helpful comments and suggestions on this manuscript.

528 This project was supported by the CMU-CIT Dean's Fellowship and the John and Claire

529 Bertucci Fellowship in Engineering to H. Parthasarathy, the Hamerschlag University

530 Professorship for D. Dzombak, and by the U.S. Department of Energy, National Energy

531 Technology Laboratory (NETL), through a support contract (DE-FE0004000) with URS

532 Energy \& Construction.

534 References:

535 APHA, AWWA and WEF (1998) Standard methods for the examination of water and 536 wastewater, 20th ed., Eds: L.S. Clesceri, A.E. Greenberg, A.D. Eaton (APHA, AWWA 537 and WEF).

538 Awakura Y, Kamei S, Majima H (1980) A kinetic study of nonoxidative dissolution of 539 galena in aqueous acid solution. Metallurgical Transactions B 11:377-381.

540 Barrett T, Anderson G (1982) The solubility of sphalerite and galena in $\mathrm{NaCl}$ brines. 541 Economic Geology 77: 1923-1933.

542 Bebie J, Schoonen M, Fuhrmann M, Strongin D (1998) Surface charge development on 543 transition metal sulfides: an electrokinetic study. Geochimica et Cosmochimica Acta 62: $544 \quad 633-642$.

545 Benjamin M (2010) Water Chemistry. (Waveland Press, Long Grove, Ill), pp. 29-30.

546 Carey F, Sundberg R (2007) Advanced Organic Chemistry. (Springer, New York, NY).

547 Corkhill C, Vaughan D (2009) Arsenopyrite oxidation--A review. Applied Geochemistry 548 24: 2342-2361.

549 Edwards J, Pearson R (1962) The factors determining nucleophilic reactivities. Journal of 550 the American Chemical Society 84: 16-24.

551 Hernan L, Morales J, Sanchez L, Tirado J, Espinos J (1995) Diffraction and XPS studies 552 of misfit layer chalcogenides intercalated with cobaltocene. Chemistry of Materials 7:

553 1576-1582.

554 Larson, R. A, and Weber, E.J. (1994) Reaction Mechanisms In Environmental Organic 555 Chemistry. Boca Raton: Lewis Publishers. Print. 
556 Lin H, Zheng Z (1996) Electrochemical oxidation of arsenopyrite in chloride solutions. 557 Hydrometallurgy 42: 411-424.

558 Metzler, D. E, and Metzler, C. M. (2001) Biochemistry. San Diego, Calif.: 559 Harcourt/Academic Press. Print.

560 Nesbitt H, Bancroft G, Pratt A, Scaini M (1998) Sulfur and iron surface states on 561 fractured pyrite surfaces. American Mineralogist 83: 1067-1076.

562 NUNez C, Espiell F, Garcia-Zayas J (1990) Kinetics of galena leaching in hydrochloric 563 acid-chloride solutions. Metallurgical Transactions B 21:11-17.

564 Ohmoto H, Hayashi K, Kajisa Y (1994) Experimental study of the solubilities of pyrite in 565 NaCl-bearing aqueous solutions at 250--350 C. Geochimica et Cosmochimica Acta 58: 566 2169-2185.

567 Parthasarathy H, Baltrus J-P, Dzombak D-A, Karamalidis A-K (2014) A method for 568 preparation and cleaning of uniformly sized arsenopyrite particles. Geochemical 569 Transactions. Accepted- In press.

570 Parthasarathy H, Dzombak D-A, Karamalidis A-K (2013) A small-scale flow-through 571 column system to determine the rates of mineral dissolution at high temperature and 572 pressure. Chemical Geology 354: 65-72.

573 Pearson R (1968) Hard and soft acids and bases, HSAB, part 1: Fundamental principles. 574 Journal of Chemical Education 45: 581.

575 Rimstidt J-D, Newcomb W (1993) Measurement and analysis of rate data: The rate of 576 reaction of ferric iron with pyrite. Geochimica et Cosmochimica Acta 57: 1919-1934.

577 Sun Z, Forsling W, Ronngren L, Sjoberg S (1991) Surface reactions in aqueous metal 578 sulfide systems. 1. Fundamental surface reactions of hydrous $\mathrm{PbS}$ and $\mathrm{ZnS}$. International 579 journal of mineral processing 33: 83-93.

580 USEPA (July 1992) Determination of Inorganic Anion by Ion Chromatography method 581 9056, Test Methods for Evaluating Solid Waste, Physical/Chemical Methods, (EPA 582 Publication SW-846).

583 Vaughan D (2006) Sulfide mineralogy and geochemistry: introduction and overview. 584 Reviews in Mineralogy and Geochemistry 61: 1-5.

585 Walker F, Schreiber M, Rimstidt J-D (2006) Kinetics of arsenopyrite oxidative 586 dissolution by oxygen. Geochimica et cosmochimica Acta 70: 1668-1676.

587 Weerasooriya R, Tobschall J (2005) Pyrite-water interactions: Effects of $\mathrm{pH}$ and $\mathrm{pFe}$ on 588 surface charge. Colloids and surfaces A: Physicochemical and Engineerig Aspects 264, 589 68-74. 